\title{
The Place of Blogs in the Modern Math World Katherine Thompson
}

The time has come for mathematicians to think seriously about blogs. What role could or should they play in disseminating information, both from whom as well as to whom? What role could or should they play in making or breaking careers? What needs to be done to transform blogs as we currently know them into something more useful or helpful or respected?

The Notices solicited this article because of a previous publication of mine [Tho18] in the Journal of Humanistic Mathematics-an online journal that specifically is informal and which regularly features math poems and short stories. When I finished the article, I was at an REU that I was co-organizing. I clicked "submit" during my morning coffee break in a collaborator's office. The content was simple: it was a description of about 20 math blogs, who ran them, how often they updated, and links to URLs.

While I don't have the statistics on my other papers, including the one resulting from the aforementioned REU, this Journal of Humanistic Mathematics article-prior perhaps to the one you're currently reading-was almost certainly the most widely-read peer-reviewed product I ever have produced. Probably the most widely-read products of mine period are my blog posts for PhD+epsilon.

The first comment then to make about blogs, and in general (expository) online mathematical writing, is that for most of us they are much more widely read than any of

Katherine Thompson is an assistant professor of mathematics at the United States Naval Academy. Her email address is kthomps@usna.edu.

For permission to reprint this article, please contact:

reprint-permission@ams.org. our traditionally-published research papers. With a blog especially, depending upon what you say and how you say it, you could become more well known than you'd like. You could receive emails, positive and negative, from complete strangers. You could be read by a public beyond the mathematical community.

The past: Journal articles? This is something perhaps for the mathematical community to consider, especially given the impact of recent events on both travel to and existence of conferences, not to mention money for grants or library subscriptions for costly journals. One way to think broadly about the nonteaching aspects of tenure packets is that the faculty member should demonstrate interaction with mathematicians outside their specific institution, that the candidate should have a name in the greater community, and a (positive) reputation. Who seems better to meet that requirement: (1) a faculty member who spends a year or more working on and then trying to publish a research paper that, once in print and assuming it's mathematically correct, is read by approximately a dozen people who then cite the paper in their year-or-longer barely-read projects, or (2) a faculty member whose monthly-updated blog has over 200 followers, an average of 100 shares per post, and a dialogue of comments ranging from those at Ivy League colleges to community colleges?

Fields medalist-and blogger-Tim Gowers in a JMM talk a few years ago started to probe at this very point. He has been a longtime proponent of doing away with traditional journals (or at least their cost) and is a staunch supporter of sites like mathoverflow. He actually wrote on his blog back in 2011: 
"What happens if somebody submits a worthy but dull paper in an unfashionable area? I've had to referee many such papers and my heart sinks every time, because I just don't really know, and, worse still, don't much care, how good they are. And yet people's careers may depend on such papers being accepted by a reasonable journal." [Gow11]

Now to be clear, Gowers is not saying that blogs and expository writing can replace research. He actually did not talk at all about expository writing. He was simply addressing accessibility of research articles and ways to increase readership, because between the costs of journals and the "interest" of the articles, readership of many published papers is laughably low. Blogs are cheap, and as long as they can grow an audience and eventually a referee process, they could reach a wider community than a traditional journal, and through comments allow for conversations that journals never could.

And indeed, the article you're reading right now is not trying to argue that expository writing can replace research-of course it can't! But this idea of publishing a research paper in a journal regardless of its expense or obscurity that few if any actually read as a measure of reputation outside a home institution, or the idea that the number and "quality" of research articles determine level of recognition might need modernizing.

This seems reminiscent of the older, not-quite-dead-yet, belief that mathematics done with the aid of computers is not "real" mathematics or that code and algorithms are not substantial contributions. Mathematicians like William Stein as late as 2016 in his talk at the Harvard Peirce Memorial Lecture Series (in which, among other things, he announced he was quitting academia effective immediately to work on SageMath full time) spoke at length about the struggles of computational mathematicians and those who want to contribute to the body of mathematics with their code and algorithms and programs: everything from citation (many software packages list all contributors in one place instead of attributing individual commands), losing students to industry because industry pays more and respects the work more, struggling to obtain grants to work on improving computational software, and failing to get faculty recognition because code is not a traditional publication [Ste16]. Code and coders, who clearly contribute to the greater body of mathematics, continue to battle with and lose against traditionalism. Blogs easily could face similar resistance.

Like computers, blogs are here to stay and again, like computers, they may increasingly be relied upon as a tool. It may be out of financial necessity. It may be out of the desire to appeal to specific groups of readers. It may be due to restrictions and limitations imposed by journals. And so how to cite blogs, how to value them, how to assess them needs to be discussed. Even with this article, citing websites and blogs was a nontrivial task-the bibtex and formatting classes would not accept URLs or websites, but rather just "notes."

And already blogs have had an impact on careers. Marquette effectively, but not permanently, fired a tenured professor because of a personal blog post [Fla18]. While years later courts ordered the professor be reinstated, and while it was a personal as opposed to a professional blog, it does bring up an interesting thought. If blog posts can have a negative impact on a career, why could they not also have a positive impact? If they have the power to take away tenure, why could they not have the power to grant it? Could blogs be turned into free advertising for the owner-a way to highlight other career accomplishments, videos of seminars on YouTube, links to papers on the arXiv? Could they be the modern C.V.?

Regardless, blogs need to be improved and expanded; we are a long way from Gowers's dream coming true of free blogs putting a dent in the expensive journal market. And forget about lack of referees for a minute. There's a bigger problem with blogs as they currently exist: they can and frequently do allow anonymous comments or comments from individuals whose identity is unauthenticated (see Gina and Gil Kalai later in this article). Beyond moderating original content to keep matters on-topic, comments would need to be moderated so that they too stay on-topic. And then of course is the reality that very little researchlevel mathematics appears or is read about on blogs-at least any that are well marketed. It will be hard for the greater research community to buy into a product that is unknown or unstructured.

The present: Defining blog success? With traditional publications, the measure of success is "was it accepted" followed by opaque notions of "journal reputation." Possibly "was it read" comes into play, but typically not. Author order in mathematics is alphabetized so that is no indication of greater success. Citation indexes aren't as crucial as they are in other fields.

Success for a blog is horribly ill-defined. Anyone can start a blog, and only a few (and $P h D+\epsilon$ is one of them) actually require an application to contribute. So the "was it accepted" analogue vacuously holds. But from the start, there is a lot more publicly-available data attached to a blog than to a traditional journal. And this data can lead to new, perhaps inflated, interpretations of success. Is success measured by longevity, total/average number of shares, to$\mathrm{tal} /$ average number of comments, total/average number of reads? Is success measured by the number of followers, or ranking in searches? Is it measured by greater press received, where that could be anything from a citation in another blog/article/paper to a mention in a nonmath setting to hate-mail?

The American Mathematical Society currently supports 11 blogs. As of May 11, 2020 here they are (perhaps with 
shortened titles to fit the table) along with their number of followers (Foll.) and average number of shares on the last 10 articles (Shares):

\begin{tabular}{|c|c|c|}
\hline Name & Foll. & Shares \\
\hline Beyond Reviews & 224 & 143.8 \\
\hline Blog on Math Blogs & 631 & 110.2 \\
\hline Capital Currents & 50 & 41.3 \\
\hline e-Mentoring Network & 10795 & 495.8 \\
\hline Graduate Student Blog & 376 & 156.3 \\
\hline inclusion/exclusion & 2776 & 1743 \\
\hline JMM Blog & 9 & NA \\
\hline Living Proof & 39 & 108.8 \\
\hline A Mathematical Word & NA & NA \\
\hline Math Mamas & 60 & 88.2 \\
\hline On Teaching and Learning & 714 & 330 \\
\hline PhD+ $\epsilon$ & 224 & 106.9 \\
\hline
\end{tabular}

Which of these blogs, just based on this chart, would be deemed the most successful? There's a clear winner in number of subscribers, with the e-Mentoring Network. There's a separate clear winner on average number of shares with inclusion/exclusion. But then blogs like Living Proof and Math Mamas have a higher average number of shares than they do subscribers; clearly more people read the blog than sign up for an email notification every time there's a new post. And that's assuming success for a blog shouldn't be defined by some other metric including the longevity of the blog, the number of contributing authors, the growth in readership over any period of time, the number of (positive) comments, the frequency of the posts.

However, there does appear to be a trend, a trend that will have to change if blogs are to have a greater role in our mathematical societies and in particular our research communities. Right now, the less about math research specifically, the more subscribers and shares. The JMM Blog, A Mathematical Word, Capital Currents - those are all near the bottom of the subscriber and share lists. Beyond Reviews is an outlier at precisely the middle of the pack. Meanwhile the highly followed and shared blogs even with their names dedicate themselves to nonresearch-specific aspects of the mathematical world including teaching and mentoring and diversity.

This is not at all meant to critique any of the AMS blog editors or contributors or posts or to suggest there is anything wrong with the content or readability of any blogs. And 11 blogs is hardly a valid sample size. But these 11 were chosen because they cover a gamut of mathspecific and general-academia topics. This article is for an AMS journal which happens to sponsor all chosen blogs in question, and these blogs collectively are probably more well known in our community than any others save Scientific American. But it does hint first that research mathematicians currently are not using, or accepting, blogs as a means of having global conversations about mathematics despite the fact that blogs are being used to have global conversations on just about every other aspect of the profession. It also hints at a need for a paradigm shift if research mathematicians are to take blogs seriously in any way. There need to be more blogs featuring wellwritten high-level research-related material, and they need to be better and more widely advertised.

The future? And now we have almost come full-circle. That which started this was an article of mine highlighting 20 blogs of various styles. I do not want to highlight a second time any of those specific blogs; however, as the purpose now is to discuss well-known (in traditional research senses) mathematicians with blogs those who would have been included had they not been mentioned before are Terry Tao and What's New [Tao07], Tim Gowers with Gowers's Weblog [Gow11], Jordan Ellenberg and Quomodocumque [Ell07] and Izabella Laba with The Accidental Mathematician [Lab07].

The blogs below were chosen to highlight additional research mathematicians as authors/owners discussing primarily research-level mathematics, but also the future of blogs in our research society. Blogs are arranged alphabetically by primary author. Note that most of these blogs also feature lists of their recommended blogs; while somewhat circular, this could provide additional reading material to those interested in research math and blogs.

- Matt Baker's math blog, aptly titled Matt Baker's Math Blog [Bak13]. His about-me page echoes many sentiments of this article regarding hopes for the future of research and blogs. Baker writes: "Many of my recent papers are kind of long, and I'm hoping to post overviews of what's in them and why a person might hypothetically care....I also want to highlight recent preprints that I find exciting...I also want to share some thoughts about teaching in the 21st century with the hope of starting interesting and/or valuable dialogues."

- Johan de Jong Stacks Project Blog [dJ10]. Posts on this site date back to 2010. While almost exclusively on algebraic geometry, what is crucial about this blog is the reference to and explanation of the greater Stacks Project. This is a collaborative effort (with almost 400 contributors involved) to produce an open-source book on algebraic geometry. The book just hit a milestone of over 7,000 pages, which in and of itself speaks to the power of opensource and modernizing collaborations.

- Gil Kalai's Combinatorics and more [Kal08]. While the "and more" can dominate from time-to-time, Kalai has offered posts regularly for over 10 years including over two dozen contributions from 
guest authors. What is especially interesting, however, is Gina Says. This is a book Kalai wrote about blogging and debating. Gina was actually Kalai in disguise, posting comments primarily on two physics blogs: Not Even Wrong by Peter Woit and The trouble with Physics by Lee Smolin. Gina also, however, infiltrated the math blogosphere, commenting on The n-Category Cafe. If nothing else, Kalai makes obvious the issue with blogs and verifying identities.

- George Shakan's math blog, with a name similar to Baker's [Sha16]. This blog was chosen because of its evolution. Shakan started this when he was still a graduate student, and the blog read like one written by a graduate student. Mostly links to PDFs of expository notes regarding background needed to understand the works of others. Slowly the posts became longer and did not just link to PDFs. And now it has become very similar in flavor to Baker's. Shakan is using this blog to describe current projects of his own. It is a creative and mathematically deep use of free advertising.

- Not Even Wrong by Peter Woit, a theoretical physicist with a best-selling book of the same name. This blog has major longevity, having been around since 2004. And it appears like it will always be Woit. "This blog reflects my own interests. If I'm not writing about X, it's usually because I'm just not very interested in X. If you are interested in $\mathrm{X}$ and want to discuss it, the great thing about the internet is that there are probably places where you can find someone who is interested, and if not, start your own blog." His more recent series of Szpiro, and the general status of the $a b c$ conjecture have been fascinating, and have generated many comments which could give some measure of success.

Clearly, mathematicians are using blogs. Clearly, organizations like the AMS sponsor blogs. Clearly, blogs can have viewership as wide or wider than traditional journals due to price alone. From personal experience, developing regular content and writing posts and monitoring comments and feedback is nontrivial work; yet these posts, even if expository, can build a reputation in the greater community and lead to both mathematical and personal conversations with individuals who otherwise would remain strangers.

And yet despite all of these advantages and despite all of the work that goes into blogs, the mathematical community has no idea what to make of them-even at the most basic level like citation. Math blogs overall are not structured, lack a formal referee process, lack monitors specifically to keep comments on-point and verify identities, and are not (well) advertised. They are extremely versatile tools, and many of their utilities like personal advertisement in a C.V. sense, or research media feeds a la any news site, remain largely untapped.

But think of what could happen if we actually started to use that which literally is at our fingertips.

\section{References}

[Bak13] Matthew Baker, Matt Baker's math blog, 2013. https://mattbaker.blog/about/.

[dJ10] A.J. de Jong, Stacks proiect blog, 2010. https://www . math . columbia.edu/ dejong/wordpress/

[Ell07] Jordan Ellenberg, Quomodocumque, 2007. https:// quomodocumque. wordpress. com/.

[Fla18] Colleen Flaherty, Divided Wisconsin supreme court backs Marquette faculty blogger, Inside Higher Ed (2018July). https://www . insidehighered.com/news/2018/07 /09/wisconsin-supreme-court-says-marquette -must-reinstate-professor-it-wanted-fire.

[Gow11] Timothy Gowers, How might we get to a new model of mathematical publishing?, 2011. https://gowers . wordpress . com/2011/10/31/how-might-we-get -to-a-new-mode1-of-mathematica1-pub7ishing/.

[Kal08] Gil Kalai, Combinatorics and more, 2008. https:// gi $7 \mathrm{kal}$ ai.wordpress.com/.

[Lab07] Izabella Laba, The accidental mathematician, 2007. https://i 1aba.wordpress.com/.

[Sha16] George Shakan, George Shakan: math blog, 2016. https://gshakan.wordpress.com/.

[Ste16] William Stein, The origins of Sagemath-creating a viable open source alternative to Magma, Maple, Mathematica, and Matlab, 2016. https://www . youtube . com/watch? $\mathrm{V}=6 \mathrm{eIoYMB} \_0 \mathrm{XC}$

[Tao07] Terrence Tao, What's new, 2007. https:// terrytao.wordpress.com/.

[Tho18] Katherine Thompson, A survey of the math blogosphere, Journal of Humanistic Mathematics 8 (2018 January), no. 1, 126-139.

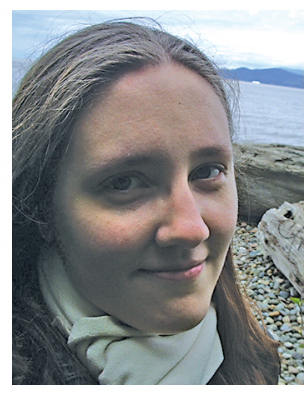

Katherine

Thompson

Credits

Photo of Katherine Thompson is courtesy of Katherine Thompson. 